\title{
FLEXURAL PERFORMANCE OF A HYBRID BRIDGE DECK WITH PULTRUDED FIBRE REINFORCED POLYMER COMPOSITE SANDWICH PANELS
}

\section{LEI WU, YUJUN QI*, WEIQING LIU \\ College of Civil Engineering, Nanjing Technical University, Nanjing, China}

Received 06 September 2017; accepted 27 June 2018

\begin{abstract}
Hybrid bridge decks with the pultruded fibre reinforced polymer have advantageous properties but easily crack because of their unsatisfactory transverse strength and shear strength. This study proposed a type of bridge deck composed of innovative pultruded fibre reinforced polymer composite sandwich panels. Using four-point bending tests, concentric wheelloading tests and eccentric wheel-loading tests combined with first-order shear deformation theory, this study investigated the failure mode, flexural capacity, deformation and ductility of hybrid bridge decks under different working conditions. Under four-point bending and concentric wheel loading, the primary failure modes for this hybrid bridge deck were shear failures along the fibre direction and buckling failure of the upper panel. Under eccentric wheel loading, the primary failure mode was a torsional failure due to the eccentric load. The bearing capacities of the hybrid bridge deck under the three working conditions were 3.8, 3.5 and 3.2 times the service load of a Class I vehicle load, respectively. Besides, the hybrid bridge deck remained in the linear elastic stress state at 2.6 times the service load, indicating that this hybrid bridge deck withstands relatively large vehicle overload without visible damage. The ductility values of this hybrid bridge deck under the three working conditions were 1.79, 2.09 and 2.00, respectively, which are
\end{abstract}

\footnotetext{
* Corresponding author. E-mail: qiyujun@njtech.edu.cn 
higher than the values for an ordinary pultruded bridge deck. Therefore, the proposed design has the relatively good energy-dissipating capacity, which improves the emergency capacity of the bridge deck.

Keywords: capacity, fibre reinforced polymer (FRP), fibre reinforced polymer sandwich panel, hybrid bridge deck, pultrusion process, southern pine.

\section{Introduction}

Fibre reinforced polymer (FRP) has been shown to be useful for constructing traffic and pedestrian bridges. Its advantages include ability to undergo bridge upgrades without strengthening the substructures, more excellent corrosion resistance than conventional materials (Ye, 2006), and ability to extend across the widths of walkways (Lee \& Hong, 2007a, 2007b; Park, 2010). Besides, under the same weight and geometric configuration, compared to a traditional bridge deck, an FRP bridge deck has a higher bearing capacity (Andor, Lengyel, Polgár, Fodor, \& Karácsonyi, 2015; Keller, 2001; Li, Tsai, Wei, \& Wang, 2014; Lu, Ling, Geng, Liu, Yang, \& Yue, 2015; Zureick, 1997).

Currently, FRP decks are classified into pultruded and sandwich decks. In the pultruded decks, orthotropic slabs are formed by bonding FRP profiles together (Bakis, Bank, Brown, Cosenza, Davalos, Lesko, ... \& Triantafillou, 2002; Keller \& Schollmayer, 2004; Liu, 2007). This type of bridge deck is a hollow thin-walled component with fibres mainly oriented along the longitudinal direction of the component (parallel to the pultruded direction) and with very few fibres oriented in the transverse direction (perpendicular to the pultrusion direction); thus, it possesses excellent longitudinal bearing performance. However, its transverse bearing performance and shear resistance are weak. These drawbacks cause the bridge deck to crack easily at the intersection of the deck slab and the web under an actual load; furthermore, they cause shear cracking in the middle of the web, which results in a unsatisfactory use efficiency of the longitudinal strength of the composite deck (Zhu, Wan, \& Liu, 2010). On the other hand, sandwich decks are composed of FRP face sheets and honeycomb, foam or light wood cores, and extra FRP webs are typically required to provide sufficient shear capacity of the core (Franke, S., Franke, B., \& Harte, 2015; Reising, Shahrooz, Hunt, Neumann, Helmicki, \& Hastak, 2004; Telang, Dumlao, Mehrabi, Ciolko, \& Gutierrez, 2006). Such a structure endows sandwich bridge decks with better shear performance and local compressive performance. The support of the core also prevents the buckling failure of FRP panels and webs, thus increasing their bearing capacity. Recently, researchers have conducted a large number of tests and theoretical studies on FRP 

conducted a transverse bending experiment on a foam-filled deck and compared its performance with that of a foamless bridge deck. The results showed that tensile stress developed in the top flange of the deck because of shear deformation and the foam inside the deck significantly mitigated that such a development of tensile stress. Park, Hong, \& Lee (2014) conducted another study. In their research, they conducted threepoint bending tests on a pultruded hollow glass fibre reinforced polymer (GFRP) bridge deck system with an adhesive joint in the bridge deck. They concluded that the pultruded hollow GFRP bridge deck has better actual bearing performance than a sandwich bridge deck with foam core and sufficiently resists deformation. However, they also found some problems with this structure. The adhesive joint concentrated the actual shear stresses in the lap joint adhesive at the edges of the spliced flanges (Hollaway, 1993). Because the adhesive joints are discrete especially in the geometric shapes, the local concentration of shear stress and deformation were exposed at the edges of the bonded flanges, which caused excessive tensile stress and deformation. Over the long term, the pavement cracks. Keller, Schaumann, \& Vallée (2007) proposed a hybrid FRP-concrete sandwich bridge deck that has a lightweight concrete core to obtain sufficient shear capacity in decks. They performed many studies, including four-point bending experiments and fatigue experiments, on FRP-balsa composite sandwich bridge decks. The sandwich structure of GFRP face sheets and structural laminated veneer lumber (LVL)-balsa core allows economical fabrication of composite bridge decks and fulfils all the requirements for serviceability, ultimate limit state, and fatigue. However, this hybrid FRP-concrete sandwich bridge deck also possesses some disadvantages; for example, the cost is relatively high, and the elastic modulus, which is critical for the stiffness of sandwich bridge decks, is low. Besides, hardly any continuous fibre for pultruded FRP is present in the transverse (perpendicular to the pultrusion) direction. Therefore, it exhibits a small bearing capacity and considerable deformation when subjected to transverse bending, and its load-displacement curve displays a strong nonlinearity in the transverse direction (Park, Kim, Lee, \& Hwang, 2005; Qiao, Davalos, \& Brown, 2000; Salim, Davalos, Qiao, \& Kiger, 1997). The nonlinearity is strongest in rectangular sections because of low shear stiffness (BazÏant \& Cedolin, 1991). Several ribs including foam ribs and honeycomb ribs have been added into rectangular sections (Davalos, Qiao, Xu, Robinson, \& Barth, 2001) to ensure that the section of the designed bridge deck better satisfies the linearity requirement. Additionally, various cross sections have also been used (Bakis, Bank, Brown, Cosenza, Davalos, Lesko, ... \& Triantafillou, 2002; Gan, Ye, \& Mai, 1999). However, simple 
rectangular sections are still preferred because they are easy to produce via pultrusion (Yashida, 2016).

To overcome the problems mentioned above, in this study, an innovative type of hybrid bridge deck with pultruded FRP composite sandwich panels was proposed. The bridge decks are assembled with pultruded composite sandwich panels, each of which is composed of a southern pine core and FRP face sheets. The hybrid bridge deck consists of four units that mechanically joined adhesive bonding and bottom bolts in the width direction. The ultimate bearing capacity, failure mode, flexural capacity, and ductility were evaluated through four-point bending tests, concentric wheel-loading tests, and eccentric wheelloading tests. Finally, the experimental results are compared to the results of the analytical model using the first-order shear deformation theory (FSDT) within the elastic region.

\section{Materials and methods}

\subsection{Design requirements}

The wheel load value in CJJ 11-2011 General Code of Design for Highway Bridges and Culverts in China is listed in Table 1. According to the code, the local loading impact coefficient of the vehicle is 1.3; therefore, its load value is taken as 1.3 times the characteristics value of the wheel load calculated from the code above, which was used in this study. Structural

Table 1. Main technical indicators of the vehicle in the CJJ 11-2011 General Code of Design for Highway Bridges and Culverts

\begin{tabular}{lcc}
\hline Item & Unit & Technical indicator \\
\hline Standard vehicle weight & $\mathrm{kN}$ & 550 \\
\hline Standard epipodium weight & $\mathrm{kN}$ & 30 \\
\hline Standard axis weight & $\mathrm{kN}$ & $2 \times 120$ \\
\hline Standard aft shaft weight & $\mathrm{kN}$ & $2 \times 140$ \\
\hline Wheelbase & $\mathrm{m}$ & $3+1.4+7+1.4$ \\
\hline Tread & $\mathrm{m}$ & 1.8 \\
\hline Landing width and length of the front wheel & $\mathrm{m}$ & $0.3 \times 0.2$ \\
\hline $\begin{array}{l}\text { Landing width and length of the middle } \\
\text { and back wheels }\end{array}$ & $\mathrm{m}$ & $0.6 \times 0.2$ \\
\hline Vehicle shape & $\mathrm{m}$ & $15 \times 2.5$ \\
\hline
\end{tabular}


analysis was conducted to examine the serviceability and structural safety of the composite sandwich deck. The maximum axle weight of the vehicle is $280.00 \mathrm{kN}$, therefore, a load of a single wheel is $70.00 \mathrm{kN}$. The wheel load plus the impact factor was $91.00 \mathrm{kN}$. Furthermore, the loading area of the hybrid bridge deck with pultruded FRP composite sandwich panels used in the concentric wheel-loading test and the eccentric wheel-loading test was $600 \times 200 \mathrm{~mm}$.

\subsection{Specimens and material properties}

This study examined a hybrid bridge deck composed of four pultruded FRP composite sandwich units manufactured by a pultrusion process at the Nanjing Spare Composites Co., Ltd. The shells are pultruded from alkali-free glass FRP and fabricated into individual units filled with a southern pine core through pultrusion. Then, these individual units are made into the FRP bridge deck via a chemical adhesive. The dimensions of a single sandwich unit are $2000 \times 90 \times 120 \mathrm{~mm}$, the wall thickness of the FRP shell is $5 \mathrm{~mm}$, the orientation of fibre along the pultrusion direction is shown in Figure $1 \mathrm{a}$, and the dimensions of a single southern pine core are $2000 \times 80 \times 110 \mathrm{~mm}$. The overall bridge deck dimensions are $2000 \times 360 \times 120 \mathrm{~mm}$. Besides, a $10 \mathrm{~mm}$ thick fine sand concrete surface course was constructed on the surface of the bridge deck to simulate the pavement of the deck surface in actual service (Figure 1b).

The sheets were manufactured according to the dimensions specified in ASTM D695-10 (2010), and the compression tests of the face sheet were performed on a universal testing machine. The DH3816 software system was used to record the static strain during test. The loading speed during the test was $2 \mathrm{~mm} / \mathrm{min}$. The mechanical parameters of the FRP face sheets were determined, as shown in Table 2.

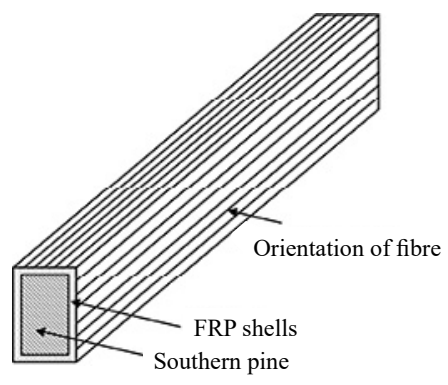

a) fibre reinforced polymer composite sandwich unit details of a Hybrid

Bridge Deck

with Pultruded

Fibre Reinforced

Polymer

Composite

Sandwich Panels

Figure 1. Hybrid bridge deck 
The wood core used in this study was made of southern pine. As the pultruded composite core, wood supports the FRP panel, delay the local buckling of the panel, and bear most of the shearing force. Therefore, its mechanical properties significantly influence the mechanical properties of the bridge deck. The density of this type of wood is $250-300 \mathrm{~kg} / \mathrm{m}^{3}$. The parallel-to-grain mechanical properties and the cross grain mechanical properties of wood vary greatly, and the parallel-to-grain properties were mainly considered in the theoretical analysis of the bridge deck compression. According to the ASTM D-143 (2000), the parallel-to-grain stress was mainly considered in the bending analysis of the southern pine cores, and the mechanical property test was conducted to determine the parallel-to-grain properties of the southern pine. Figure 2 shows the experimental setup and Table 3 presents the results for the core.

Table 2. Fundamental mechanical properties of the face sheet

\begin{tabular}{cccccc}
\hline & $\begin{array}{c}\text { Compressive } \\
\text { strength, } \\
\mathbf{M P a}\end{array}$ & $\begin{array}{c}\text { Tensile } \\
\text { strength, } \\
\mathbf{M P a}\end{array}$ & $\begin{array}{c}\text { Shear } \\
\text { strength, } \\
\mathbf{M P a}\end{array}$ & $\begin{array}{c}\text { Shear } \\
\text { modulus, } \\
\mathbf{G P a}\end{array}$ & $\begin{array}{c}\text { Elastic } \\
\text { modulus, } \\
\mathbf{G P a}\end{array}$ \\
\hline $\begin{array}{c}\text { Fibre reinforced } \\
\text { polymer }\end{array}$ & 163.0 & 389.4 & 8.5 & 3.1 & 22.0 \\
\hline
\end{tabular}

Table 3. Fundamental mechanical properties of longitudinal wood

\begin{tabular}{ccccc}
\hline & $\begin{array}{c}\text { Compressive } \\
\text { strength, MPa }\end{array}$ & $\begin{array}{c}\text { Elastic modulus, } \\
\text { GPa }\end{array}$ & $\begin{array}{c}\text { Shear strength, } \\
\mathbf{M P a}\end{array}$ & $\begin{array}{c}\text { Shear modulus, } \\
\text { GPa }\end{array}$ \\
\hline Southern pine & 21.5 & 49.8 & 5.0 & 1.4 \\
\hline
\end{tabular}

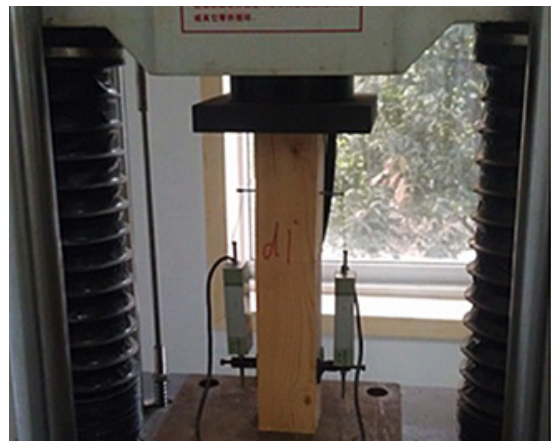

a) compression test

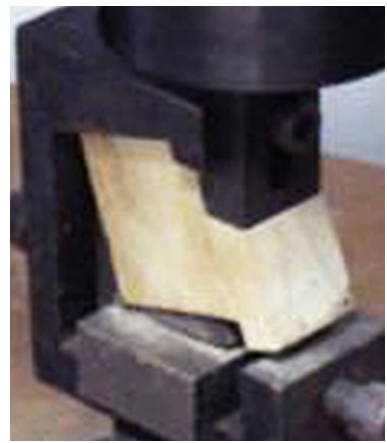

b) shear test

Figure 2. Material test of longitudinal wooden specimens 


\subsection{Loading conditions and measurement scheme}

This study investigated the mechanical performance of an innovative type of hybrid bridge deck under different loading conditions and evaluated whether this deck satisfies the application requirements. Therefore, were studied three different working conditions through the four-point bending test, concentric wheel-loading test and eccentric wheel-loading test, which were named Load Case 1, Load Case 2, and Load Case 3, respectively.

\subsubsection{Load Case 1}

To obtain accurate test results of the bending moment distribution in pure bending, the first experiment that was conducted was the fourpoint static bending test. The total length of the hybrid bridge deck was $2000 \mathrm{~mm}$. One of the ends of the bridge deck was placed on a fixed hinged support, and the other end was placed right above the roller support, with an actual span of $1800 \mathrm{~mm}$. The loads were applied $650 \mathrm{~mm}$ from the two supports. Steel beam blocks at $100 \times 100 \times 360 \mathrm{~mm}$ were transversely placed between the loading point and the loading head, and a reaction frame and jack were used for to apply the load. Figure 3 shows the specific setup. Displacement meters and 5AA strain gauges were used to measure the displacement and strain, respectively. Five displacement meters were arranged with one each above the two supports, at the bottom of the loading point and the vertical midspan. The 5AA strain gauges were placed on the FRP surface, on the surface course and at the bottom of the bridge deck. Figure 4 shows the setup of the four-point bending test.

The loading scheme was as follows: a graded loading system was adopted, with load increments of $10.00 \mathrm{kN}$ and loading intervals

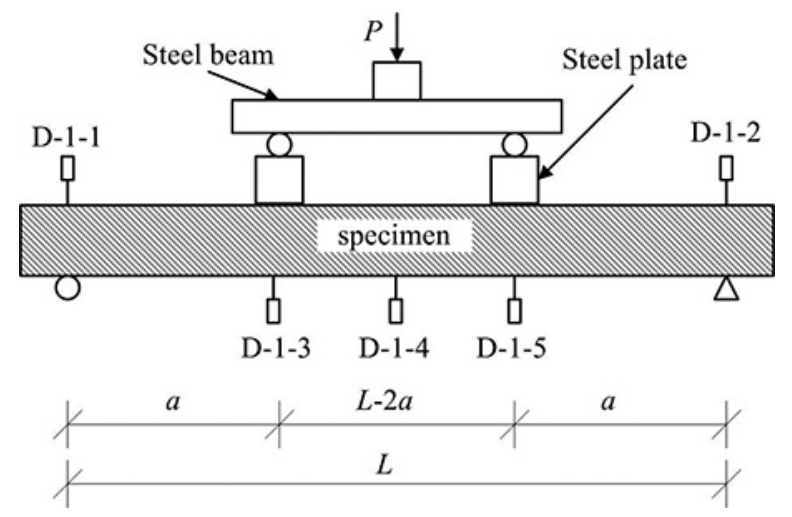

Figure 3. Four-point bending loading device of a Hybrid

Bridge Deck 


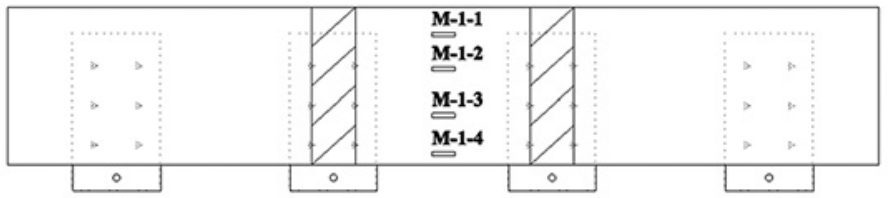

a) the top of the hybrid bridge deck

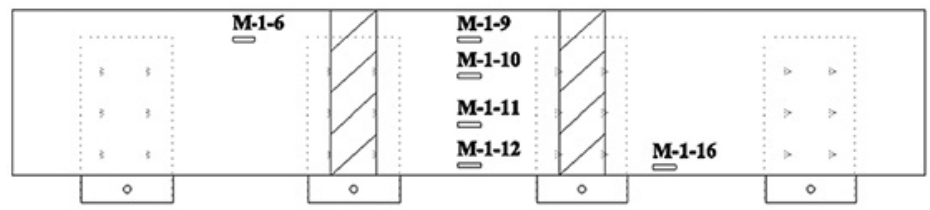

b) the concrete surface

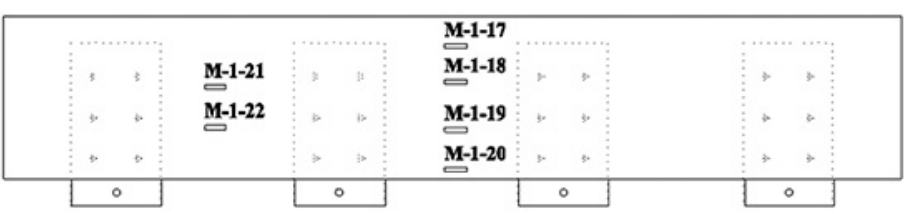

c) the bottom of the hybrid bridge deck

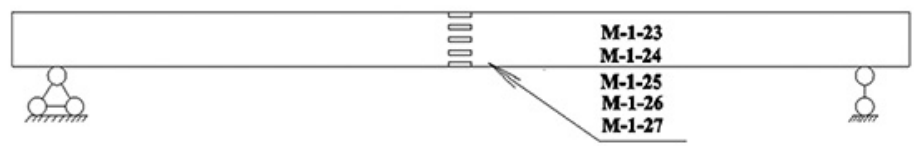

d) the side of the hybrid bridge deck

Figure 4. The arrangement of the four-point bending loading measuring points

of approximately $1 \mathrm{~min}$ for two load levels. To facilitate the full development of deformation and data collection, when the stiffness of the specimen significantly decreased, the load increment was changed to $5.00 \mathrm{kN}$. When the specimen deformation was sufficiently large or when the specimen was damaged, loading was stopped. The readings of the three displacement gauges at the bottom of the specimen and of the strain gauges on the three different face sheets were observed to determine whether coordinated deformation occurred.

\subsubsection{Load Case 2}

To simulate the actual situation of a bridge under service load, the load level and the loading range of the FRP bridge deck in the model test were determined according to the CJJ 11-2011. Steel beam blocks at $600 \times 200 \times 200 \mathrm{~mm}$ were transversely arranged between the loading point and the loading head during the test. Figure 5 shows the loading device used to simulate the Level I single-wheel pressure. The loading area was $600 \times 200 \mathrm{~mm}$ at the midspan, and the measuring points were 


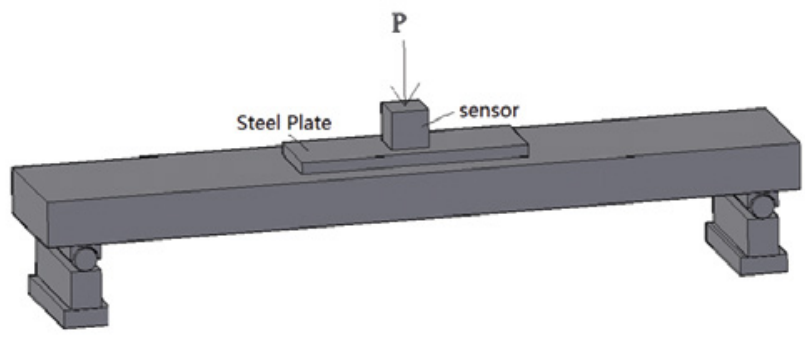

Figure 5. Concentric wheel-loading test setup

b) the concrete surface

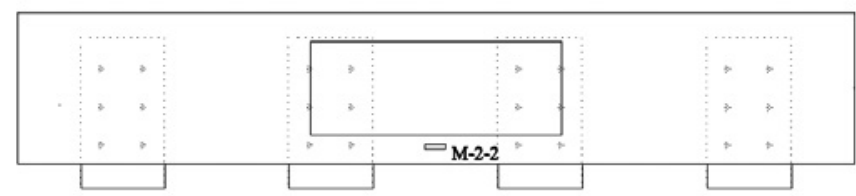

a) the top of the hybrid bridge deck

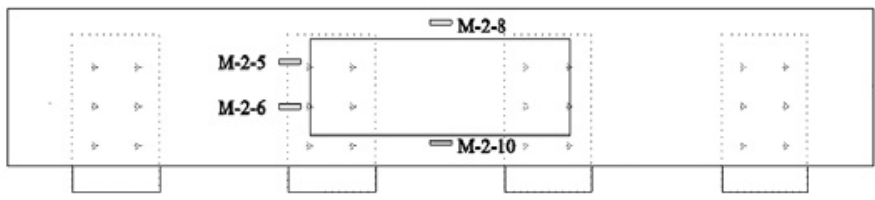

c) the bottom of the hybrid bridge deck

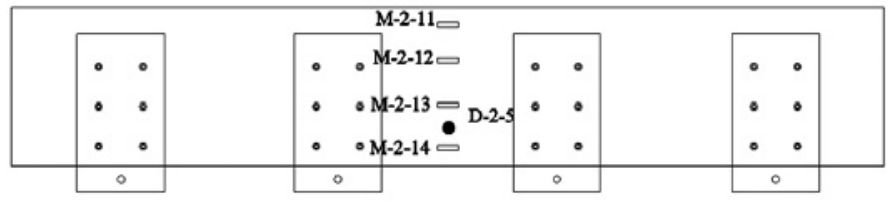

Figure 6. The arrangement of the measuring points in the concentric wheel-loading test

arranged as shown in Figure 6. The loading scheme was the same as that for Load Case 1. The critical measurement values were the strain measured at the indicator loading area and the deflection measured at the corresponding bottom measuring point. The differences in the mechanical properties at these locations were compared.

\subsubsection{Load Case 3}

To simulate a single-wheel load in practical engineering applications and to study the eccentric stress of a local wheel load and the torsion failure mode, an eccentric wheel-loading test was conducted. Compared 
Figure 7. Eccentric wheel-loading test setup

Figure 8. Torsion angle relation
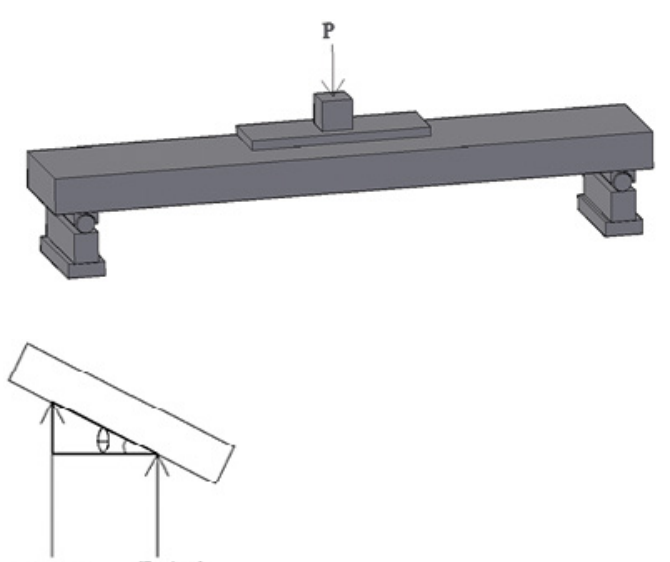

D-3-8

D-3-6

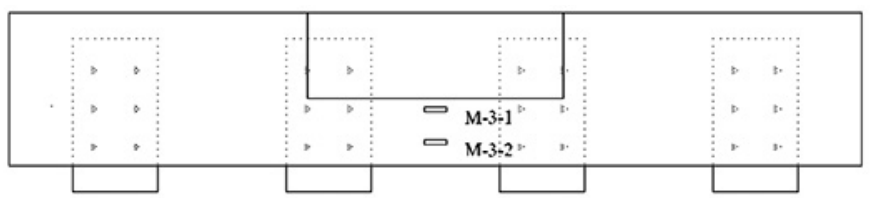

a) the top of the hybrid bridge deck

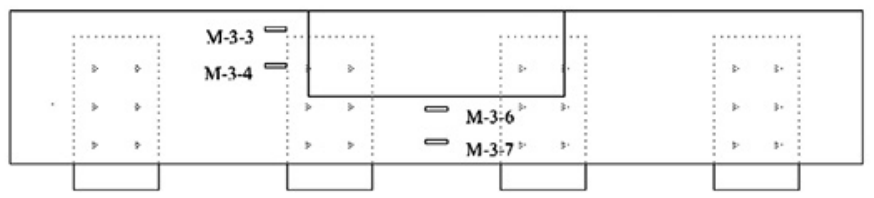

b) the concrete surface

c) the bottom of the hybrid bridge deck

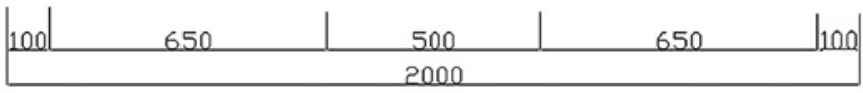

Figure 9. The arrangement of the measuring points in the eccentric wheel-loading test

to the loading conditions in the previous test, the load position was shifted toward one side, with an eccentricity of $80 \mathrm{~mm}$. Figure 7 shows the schematic diagram of this test. The loading area was still $600 \times 200 \mathrm{~mm}$, and the loading scheme was the same as the working 
conditions in Load Case 1. The observed indicators were the strain values around the loading area and the strain values at the bottom of the bridge deck. The strain values of the displacement meters on both sides of the loading points, namely, D-3-8 and D-3-6, were used to calculate the specific torsion angle. Figure 8 shows the schematic diagram of the torsion angle, and Figure 9 shows the arrangement of measuring point.

\section{Results and discussion}

\subsection{Four-point bending}

\subsubsection{Flexural failure modes and curve description}

Under the working conditions of Load Case 1, fine cracks appeared at the initial stage of the loading process, and a white colour appeared on the side of the midspan. D-1-4 was the measuring point located at the midspan of the bottom. The bridge panel displayed a clear linear phase until $310.00 \mathrm{kN}$, followed by large cracks and decreased load. When the loading continued to $348.60 \mathrm{kN}$, the midspan deflection was the largest at approximately $40.40 \mathrm{~mm}$, which was approximately $1 / 45$ of the clear span of the bridge. This result indicated substantial improvements in the bearing capacity and deflection for the proposed composite bridge deck. For comparison, Feng \& Ye (2004) performed a static load test and analysis for hollow GFRP panels and obtained a midspan deflection corresponding to the maximum load of $24.13 \mathrm{~mm}$, which was approximately $1 / 50$ of the

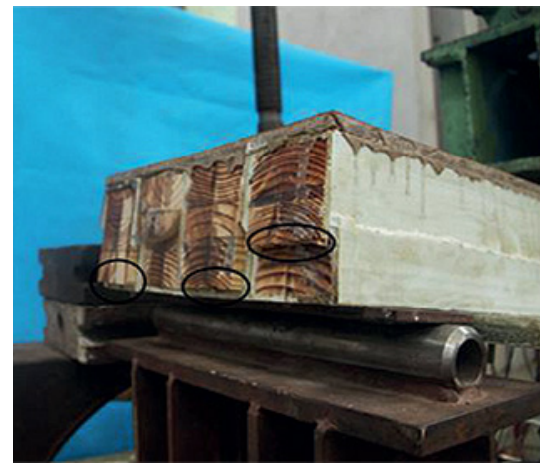

a) slight extrusion of the wood core at the end

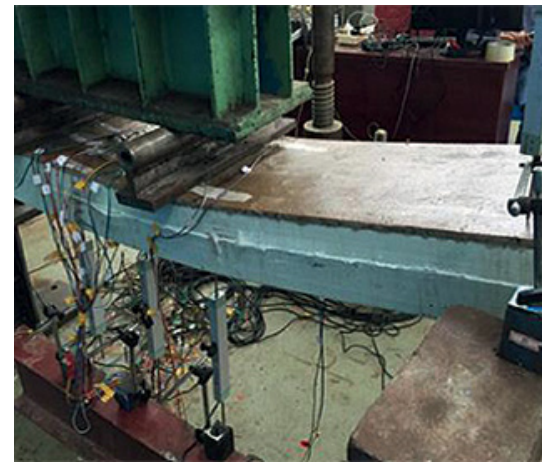

b) complete cracking of fibre reinforced polymer

Figure 10. The failure mode of specimens 
span. After reaching the maximum deflection, the load began to decrease; when the load decreased to $290.00 \mathrm{kN}$, the deflection was $46 \mathrm{~mm}$. At this load, peeling of the FRP was observed on both sides along with slight extrusion of the southern pine core at the endpoint, as shown in Figure 10. This result occurred because, under the action of the load, the southern pine core sustained a shear force, the FRP web cracks, and the cracks run along the longitudinal direction; then, the ultimate load was reached. At the ultimate load, the fibre reinforcement layer and the internal FRP components separated. Then, when the specimen did not experience bending failure of the regular section, the stress of the web along the fibre direction reached its maximum, and shear failure occurred. With continued loading, the southern pine core and the external FRP did not experience shear-deboning failure at the end. At this point, the rigidity of the bridge deck decreased, and the corresponding load-displacement curve decreased. Then, the distance among the southern pine cores at the composite sandwich beam end increased to $3 \mathrm{~mm}$. The corresponding loading curve decreased slowly, and the displacement gradually increased. When the load decreased to $230.00 \mathrm{kN}$, the displacement was $51.11 \mathrm{~mm}$, which is $1 / 35$ of the clear span of the beam. Then, the load slowly increased with continued loading, corresponding to the flat part of the curve in Figure 11a. Finally, the specimen was damaged, and the load was removed. The maximum load for this test was $348.60 \mathrm{kN}$, which is 3.8 times the service load of $91.00 \mathrm{kN}$. Zhu, Wan, \& Liu (2010) reported that the maximum load of the hollow FRP bridge deck was 1.1 times the service load. The results in this study indicated that a pultruded FRP

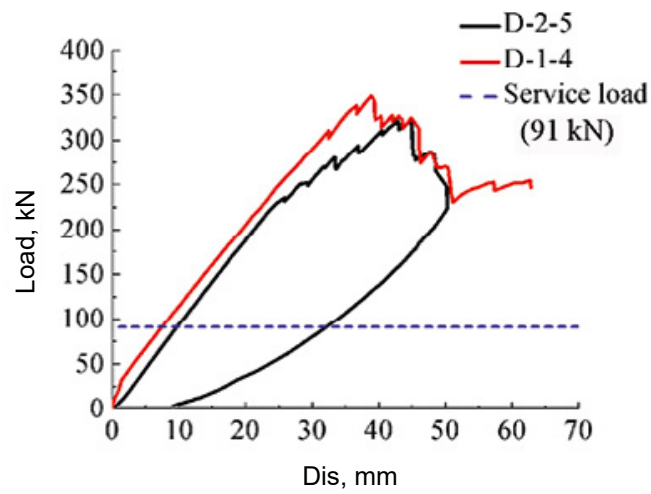

a) load-displacement

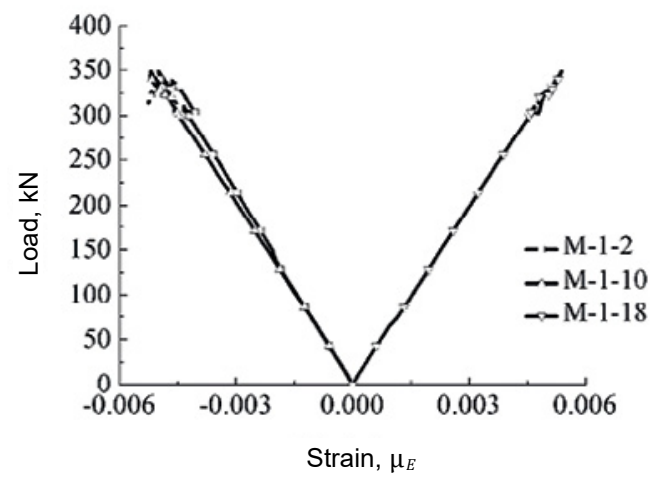

b) load strain

Figure 11. Load-displacement response 
sandwich bridge deck has a high bearing capacity. Therefore, it satisfies the requirements of a Class I vehicle load. Besides, this hybrid bridge deck has better qualities, especially in terms of the surface quality, and the quality of the pultrusion process is controllable, compared to those of composite sandwich panels manufactured via the hand layer up process and vacuum infusion process (Fairuz, 2014). Thus, this study provides an excellent foundation for future research.

In Load Case 1, the three measuring points M-1-2, M-1-10 and M-1-18 were located at the FRP surface, on the surface course, and at the bottom of the bridge deck, respectively. The strain in the midspan section of each specimen type varied linearly with the load, which was consistent with the results reported in the literature (Manalo, Aravinthan, \& Karunasena, 2010). This result indicated that the stress in this section increased evenly throughout the loading process. When the load was $310.00 \mathrm{kN}$, the strains at measuring points M-1-2, M-1-10 and M-1-18 on the corresponding load-strain curve in Figure 11b were approximately $-0.00434,-0.0046$ and 0.00468 . The strain values at M-1-2 and M-1-10 were close to each other, and the absolute values of the strain at all three locations were close together. These results indicate that in the fourpoint bending test, the FRP surface, the surface course and the bottom of the bridge deck experienced coordinated deformation and similar stress mechanisms. Therefore, the strain values were also similar. With continued loading, the strain continued to increase to a maximum value of $348.60 \mathrm{kN}$. Then, the load decreased, and the strain decreased accordingly, followed by specimen failure and the removal of the load. The splicing process enables the continuous manufacturing of this type of component and ensures that the structure meets the reasonable use and design requirements in the limit state.

\subsubsection{Analysis of the plane section assumption}

The strain distribution along the height of the midspan section is shown in Figure 12 (the specific locations are shown in Figure 4). Figure 12 shows that the specimen conforms to the plane section assumption before being loaded to $0.2 P_{u}$. Raftery \& Whelan (2014) indicated that the reinforcement in the tensile zone lowered the location of the neutral axis. In this study, when the load was above $0.2 P_{u}$, the lower two measuring points still showed linear trends, conforming to the plane section assumption. However, the sectional curvature of the upper two measuring points changed, and displacement occurred on the strain distribution curve. The main reason for this phenomenon was that the FRP deboned and the limit load was reached simultaneously; shear failure occurred between the fibre reinforcement layer and the internal southern pine core, and the rigidity decreased. When the compressive of a Hybrid

Bridge Deck with Pultruded Fibre Reinforced Polymer Composite Sandwich Panels 


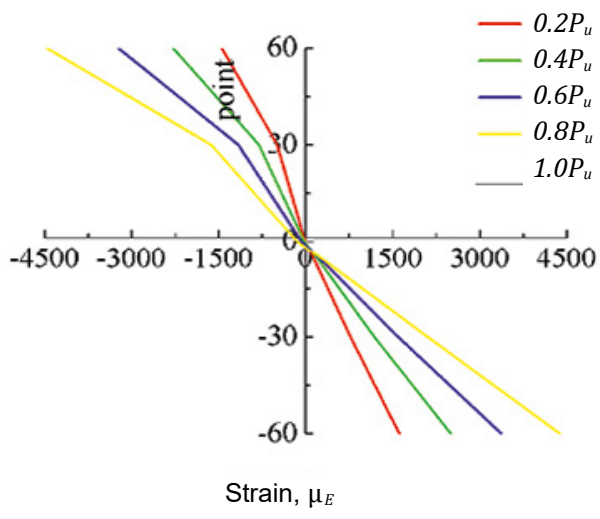

Figure 12. Strain curve of the section

strain at the top of the side reached 0.001, the failure between the FRP and the southern pine core became more pronounced. With increasing load, the displacement curve became increasingly visible and violated the plane section assumption. Furthermore, the bending moment effect increased with increasing load, and the tensile stress in the lower part of the bridge deck section eventually exceeded the tensile strength. In other words, the upper ply of the bridge deck was no longer in service, and the bottom of the bridge deck sustained all the tensile stress. During this process, the neutral axis of the section gradually moved up. Compared to the nonlinear behaviour in the cross-section of the experiment by Lu, Ling, Geng, Liu, Yang, \& Yue (2015), this movement was more pronounced and mainly manifested in the tensile zone. In the test by Lu, Ling, Geng, Liu, Yang, \& Yue (2015), when the load exceeded $15.00 \mathrm{kN}$, the tensile zone violated the plane section assumption. In contrast, in this test, when $0.2 P_{u}$, which corresponded to a load of $69.70 \mathrm{kN}$, was exceeded, the results still showed a linear increase. Thus, the innovative bridge deck has a stronger elastic segment and withstands greater vehicle overload without causing significant damage. In theory, the "pseudo plane section assumption" provides the necessary deformation coordination conditions for bending stress calculation and flexural bearing capacity calculation of the beam in bending (Wu, Ye, Wan, \& Hu, 2005).

\subsection{Concentric wheel-loading test}

\subsubsection{Flexural failure modes and curve description}

The load-displacement curve of Load Case 2 is shown in Figure 11a. In the concentric loading test, before the load reached $235.20 \mathrm{kN}$, the curve was almost linear. At a load of $35.20 \mathrm{kN}$, the displacement was $25.92 \mathrm{~mm}$. 
Then, the rate of increase of the displacement decreased because diagonal cracks appeared in the surface course. With continued loading, the cracks continued to expand. The corresponding load-displacement curve slowly increased to a maximum value of $320.70 \mathrm{kN}$. At this point, the midspan deflection was $41.60 \mathrm{~mm}$, which is approximately 1/40 of the clear beam span. When the load continued to increase, a loud sound was heard, and the crack on the side of the surface course ran through, separating the single composite sandwich beam on the front side from the bridge deck on the backside, as shown in Figure 13. The primary cause of this failure was that the single composite sandwich beam on the front side and the steel plate at the bottom were partially connected. At this time, the load began to decrease. With continued loading, the load continued to decrease, while the deflection increased. When the load was decreased to $226.21 \mathrm{kN}$, the deflection was $50.33 \mathrm{~mm}$, which was approximately $1 / 36$ of the clear span. At this point, the FRP on the flank of the bridge deck wrinkled, and the face sheets began to debond, indicating that the specimen was severely damaged, and then the load was removed. Comparing the midspan load-displacement curve under two different working conditions showed that the load-displacement curve of the four-point bending test had an extended-linearity when compared to that of the concentric wheel-loading test. This difference was caused by the relatively large strain in the four-point bending test, and the relatively small strain in the concentric wheel-loading test, which reached the maximum value first and showed an evident stress concentration. Furthermore, the maximum bearing capacity in the concentric wheel-loading test was smaller than the bearing capacity in

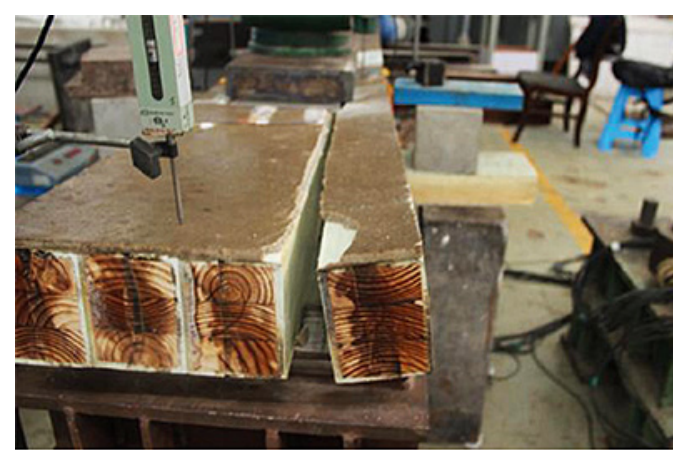

a) separation of a single composite sandwich beam

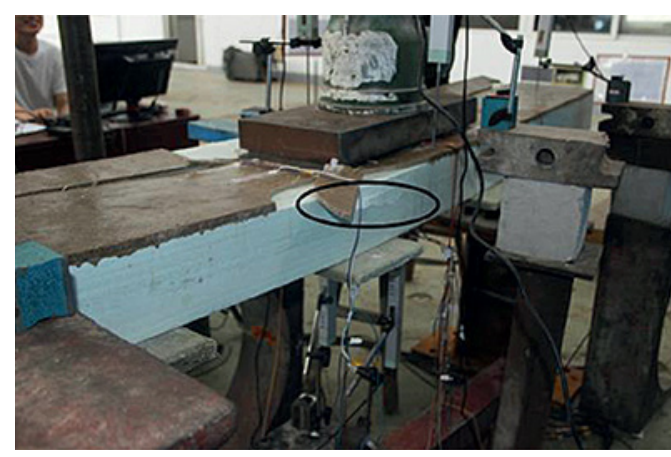

b) wrinkling of the fibre reinforced polymer on the flank and debonding of the face sheets

Figure 13. Specimen failure mode 
the four-point bending test. In addition, the linear sections were longer in Load Case 1 and Load Case 2 than that in the test by Triandafilou \& O'Connor (2010). In that study, foam and honeycomb structures were used as the core of the bridge deck in the four-point bending test. Although the foam and honeycomb core prolonged the life of the bridge deck, it decreased the bearing capacity. By contrast, the hybrid bridge deck with pultruded FRP composite sandwich panels improved the bearing capacity, resulting in a structure with a broader application than the bridge deck proposed by Triandafilou \& O'Connor (2010). Compared to reinforced concrete bridge decks (Ye, 2006), the proposed hybrid bridge deck with pultruded FRP composite sandwich panels displays improved stiffness and strength; furthermore, it is convenient and efficient because of its lightweight compared to reinforced concrete panels of the same dimensions.

The load-strain curve is shown in Figure 14. The measuring points M-2-2 and M-2-14 were located at the FRP surface and the bottom of the bridge deck, respectively, as shown in Figure 6. Before the load reached $235.20 \mathrm{kN}$, the load-strain curve increased almost linearly, and the strain values of the corresponding measuring points were -0.00349 and 0.00272 , respectively. The strain increased with increasing load before reaching the maximum load of $320.70 \mathrm{kN}$. Then, the single composite sandwich beam on the front side and the bridge deck on the backside were separated, and the cracks on one side ran through the surface course. Therefore, the load decreased, and the strain at the measuring points on the load-strain curve decreased accordingly, leading to uneven stress on the bridge deck, with an actual bearing capacity that was greater than the measured bearing capacity.

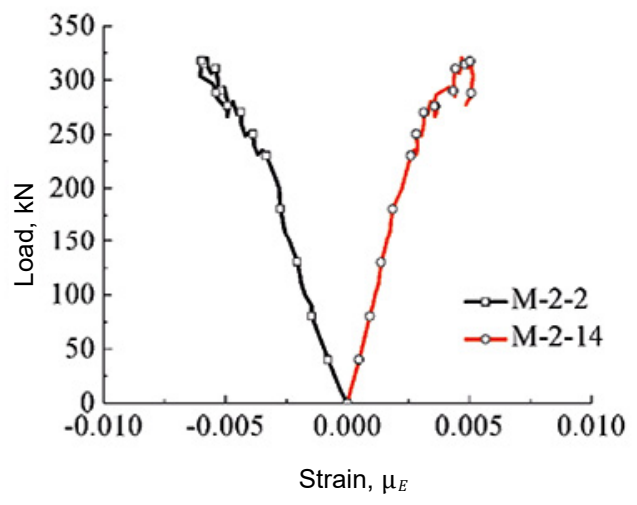

Figure 14. Load-displacement response 


\subsubsection{Strength and stiffness}

The test results of the hybrid bridge deck, including the ultimate bending strength $\left(P_{\mathrm{u}}\right)$ and elastic bending stiffness $\left(K_{e}\right)$, are summarized in Table 4 . The effective bending stiffness $K_{e}$ of the sandwich beams was used to evaluate their resistance to lateral loads in this study, considering the combined effect of bending and shear deformation. $K_{e}$ of the specimens was calculated from the initial linear elastic portion of the load-deflection curve for each specimen using the following Eq. (1):

$$
K_{\mathrm{e}}=\frac{P_{\mathrm{y}}}{f_{\mathrm{y}}},
$$

where $P_{y}$ and $f_{y}$ are the load and midspan deflection of the working conditions at the end of the linear range in the load-deflection curve for the specimen, respectively.

The ultimate bending strength $P_{u}$ and elastic bending stiffness $K_{e}$ were $348.60 \mathrm{kN}$ and $9.55 \mathrm{kN} / \mathrm{mm}$ for Load Case 1 and $320.70 \mathrm{kN}$ and $9.07 \mathrm{kN} / \mathrm{mm}$ for Load Case 2, respectively. For Load Case 1, the ultimate bending strength $P_{u}$ and elastic bending stiffness $K_{e}$ were approximately 1.09 and 1.06 times those of Load Case 2, and the contributions of the four-point bending and concentric wheel-loading tests are similar. Therefore, the corresponding load strain and deflection values were also approximately equal, and the deformation stress was able to be coordinated. Thus, the bending strength and elastic bending stiffness were relatively similar. This result also shows that the design bearing capacity of the two working conditions satisfies the engineering safety design requirements even under the condition of specimen failure. The specific strain distribution of the cross-section is shown in Figure 12. When the compressive strain at the top of the side reached 0.001 , damage appeared between the FRP and the wood core. As the load continued to increase, the lateral tensile strain increased linearly, which also shows that the connection steel plate at the bottom improved the actual bearing capacity of the bridge deck; thus, the deck better meets the usual engineering use requirements.

Table 4. Mechanical parameters of the working conditions

\begin{tabular}{ccccc}
\hline $\begin{array}{c}\text { Working } \\
\text { conditions }\end{array}$ & $\begin{array}{c}\boldsymbol{P}_{\mathbf{u}} \\
\mathbf{k N}\end{array}$ & $\begin{array}{c}\boldsymbol{P}_{\mathbf{y}} \\
\mathbf{k N}\end{array}$ & $\begin{array}{c}\boldsymbol{f}_{\mathbf{y}} \\
\mathbf{m m}\end{array}$ & $\begin{array}{c}\boldsymbol{K}_{\mathbf{e}} \\
\mathbf{k N} / \mathbf{m m}\end{array}$ \\
\hline Load Case 1 & 348.60 & 310.00 & 32.46 & 9.55 \\
\hline Load Case 2 & 320.70 & 235.20 & 25.92 & 9.07 \\
\hline
\end{tabular}

of a Hybrid

Bridge Deck 


\subsection{Eccentric wheel-loading test}

\subsubsection{Failure modes and curve description}

Load Case 3, which was the eccentric wheel-loading test, had a different loading mode than the previous two cases, and its failure mode was quite similar. When the load started at $110.00 \mathrm{kN}$, several cracks appeared at a $45^{\circ}$ angle on the surface course of the bridge deck, as shown in Figure 15a. With continued loading, the cracks expanded and extended. The load-displacement curve showed a linear increase until $250.00 \mathrm{kN}$. The measuring points D-3-6 and D-3-8 were located at the bottom of the bridge deck, as shown in Figure 9. At a load of $250.00 \mathrm{kN}$, the displacements at measuring points D-3-6 and D-3-8 were $32.43 \mathrm{~mm}$ and $23.46 \mathrm{~mm}$, respectively. The displacement on one side of the loading point, namely, measuring point D-3-6, was greater than that of the measuring point D-3-8, mainly due to the eccentric action of the wheel load.

In addition, with continued loading, the crack extended to the endpoint of the bridge deck, and the corresponding load decreased nonlinearly on the displacement curve. Under torsion, the cracks ran along the surface course and through the bridge deck at a $45^{\circ}$ angle, and the surface course wrinkled along the crack. Simultaneously, cracks appeared in the composite fibre at the front side and extended to one side, as shown in Figure 15b. At this point, the load reached a maximum value of $289.70 \mathrm{kN}$, and the deflections at measuring points D-3-6 and D-3-8 were $43.25 \mathrm{~mm}$ and $28.43 \mathrm{~mm}$, which are $1 / 42$ and $1 / 63$ of the clear span, respectively. With continued loading, the cracks in the composite fibre on the front side completely ran through the bridge deck, and the load began to decrease. The deck almost tilted at $230.00 \mathrm{kN}$, and the specimen was entirely damaged by torsion. At this point, the load was stopped and removed. The

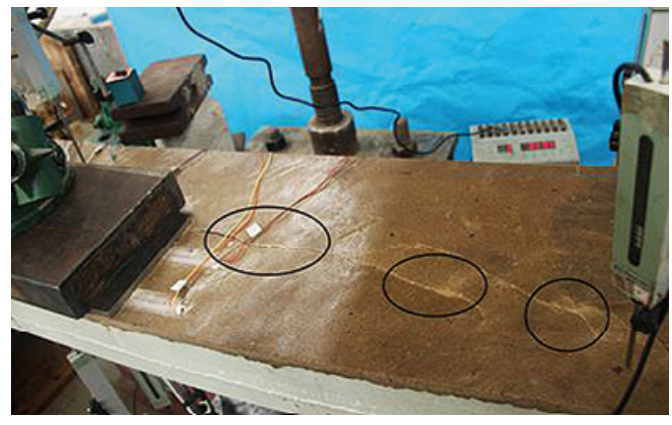

a) cracks on the loading side

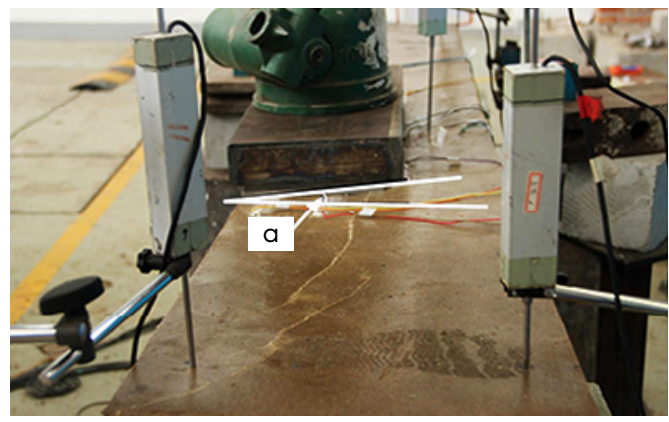

b) torsion failure ( $a$ - indicates the torsion angle)

Figure 15. Specimen failure mode 
apparent residual deformation was seen in the load-displacement curve, and the maximum load is approximately 3.2 times the service load of $91.00 \mathrm{kN}$. Ji, Byun, Lee, Son, \& Ma (2011) proposed a composite sandwich panel comprised of a wrapped hybrid core of a GFRP grid and multiple steel box cells with an upper GFRP layer (UFL) and lower GFRP layer (LFL) and conducted three-point bending testing. The results show that the maximum load of this type of bridge deck was $491.00 \mathrm{kN}$, approximately four times the service load of $122.30 \mathrm{kN}$. Both their results and the results of this study demonstrate that composite sandwich bridge decks have a very high bearing capacity, for similar section sizes. In addition, even for the torsion damage under the eccentric action of a single-wheel load, the actual bearing capacity of the bridge deck is sufficient for meeting the safety requirements and has been fully utilized.

Similarly, the load-displacement response Figure 16 was obtained from the test data in the eccentric wheel-loading test. The measuring point M-3-7 is located on the surface course, and measuring points M-3-11 and M-3-14 are located on the two sides of the bridge deck, as shown in Figure 9. Similarly, at the end of the linear segment, i.e., when the load was approximately $250.00 \mathrm{kN}$, the strain values of the measuring points M-3-7, M-3-11, and M-3-14 were -0.00287, 0.00395, and 0.00306, respectively. The measuring points M-3-7 and M-3-14 were located on the upper and lower sides of the non-loading end, respectively, and their strain values were approximately equal. Thus, under loading, the upper and lower surfaces were able to undergo coordinated deformation, and the stress failed to reach its maximum value. By contrast, the stress at measuring point M-3-11 was larger than at the other two measuring points as M-3-11 was located directly below of a Hybrid

Bridge Deck

with Pultruded

Fibre Reinforced

Polymer

Composite

Sandwich Panels

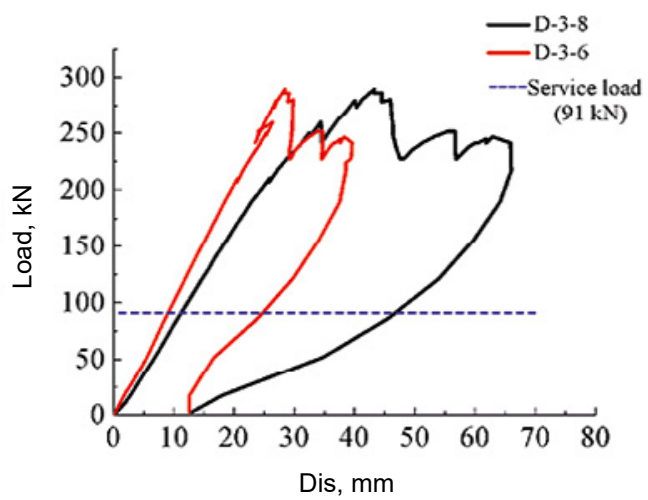

a) load-displacement

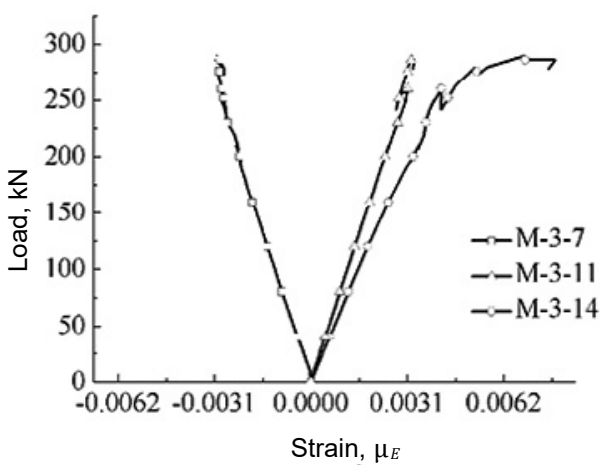

b) load-strain

Figure 16. Load-displacement response 
the loading end and sustained considerable stress. Under the condition of continued loading, this location reached a maximum load of $289.70 \mathrm{kN}$. At this point, as the cracks spread to the surface, the composite fibre at the front side ruptured, and the stresses on the two sides of the component were uneven. In addition, the single composite sandwich beam appeared to slip at a distance of approximately $10 \mathrm{~mm}$. The load on the corresponding load-strain curve decreased. With continued loading, the strain slowly increased until the component tilted severely. Then, the loading was stopped as ultimate failure had already occurred.

\subsubsection{Torsion angle}

In the eccentric wheel-loading test, the two sides of the bridge deck sustained non-uniform stress, and a torsional failure occurred. The torsion angle at torsional failure was able to be determined using the measuring points D-3-6 and D-3-8 at the bottom of the bridge deck and the distance $d$ among them, combined with the setup in Figure 8. The load-torsional angle relation is shown in Figure 17. At the beginning of loading, several cracks appeared on the surface, and the angle $\theta$ steadily increased before reaching nonlinearity. Then, the cracks extended to the endpoint, and the load undulated. The load continued to increase to the maximum value, and the $\theta$ discontinued to increase. At this time, cracks appeared in the composite fibre on the front side of the component. With continued loading, fibre rupture extended to one side until it ran through the deck when the load began to decrease. The corresponding deflection increased slowly. At the same time, the ply wrinkled, and the specimen was severely damaged. The $\operatorname{dip} \theta$ corresponding to the load $217.24 \mathrm{kN}$ was approximately 0.15 . To draw a conclusion, with increasing load, the dip gradually increases, the torsional stiffness of the specimen decreases, and the corresponding bearing capacity of the bridge deck also decreases.

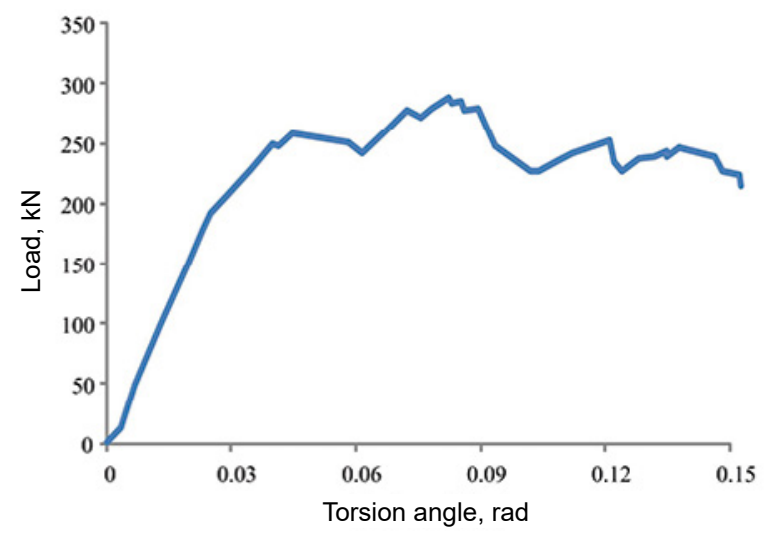

Figure 17. Load-torsional angle curve 


\subsection{Ductility}

The ductility of a beam is defined as its ability to sustain inelastic deformation without a decrease in its load carrying capacity before failure. In this study, the ductility index $\mu_{E}$ was adopted to evaluate the ductility performance of the sandwich beams, which is determined by the total energy $W_{t}$ and elastic energy $W_{e}$, as follows (Eq. (2)):

$$
\mu_{E}=\frac{1}{2}\left(\frac{W_{t}}{W_{e}}+1\right),
$$

where $W_{t}$ and $W_{e}$ are calculated as the area under the load-deflection curve and the load-deflection up to the elastic limit, respectively. The calculated total energy $W_{t}$, elastic energy $W_{e}$ and ductility index $\mu_{E}$ of all the sandwich specimens tested in this study are listed in Table 5.

Load Case 1 had the minimum ductility index $\mu_{E}$ (average value is 1.43) because the ductility index in was the smallest Load Case 1 . The main reason for this result was that the linear segment with uniform stress under the four-point bending test was much longer, and the corresponding $W_{e}$ were relatively large; therefore, the ductility index was small. The mean ductility indexes $\mu_{E}$ of Load Case 2 and Load Case 3 were 2.09 and 2.00 , which were $16.80 \%$ and $11.70 \%$ greater than that of Load Case 1, respectively. In particular, the average mean ductility index of Load Case 2 was significantly larger than those of Load Case 1 and Load Case 3 and much higher than the mean ductility index 1.96. In the concentric wheel-loading test in Load Case 2, one piece of wood on the front side was damaged under stress and was separated, and the main stress points were the three composite columns at the backside. Thus, the bridge deck sustained uneven stress, resulting in the relatively short elastic stage. Therefore, the obtained ductility coefficient was relatively large. The ductility index of Load Case 3 was slightly larger than that of Load Case 1. The main reason for this difference was that in the eccentric wheel-loading test in Load Case 3, the uneven deformation on both sides and the uneven stress resulted in a larger ductility index. This study shows that the ductility index reflects the application of the bridge deck in engineering so that severe brittle failure is able to be prevented.

Table 5. Energy ductility index of the tested beam specimens

\begin{tabular}{lllc}
\hline Specimens & $\begin{array}{l}\boldsymbol{W}_{\mathbf{e}} \\
\mathbf{k N} / \mathbf{m m}\end{array}$ & $\begin{array}{l}\boldsymbol{W}_{\mathbf{t}} \\
\mathbf{k N} / \mathbf{m m}\end{array}$ & $\begin{array}{l}\text { Energy ductility } \\
\text { index, } \boldsymbol{\mu}_{\mathrm{E}}\end{array}$ \\
\hline Load Case 1 & 5485.12 & 14177.41 & 1.79 \\
\hline Load Case 2 & 3132.71 & 9973.86 & 2.09 \\
\hline Load Case 3 & 3808.83 & 11421.49 & 2.00 \\
\hline
\end{tabular}




\section{Theoretical analysis}

To evaluate the test results and to obtain reasonable results, the classical Euler-Bernoulli beam theory was used in this section. Although the classical Euler-Bernoulli beam theory is applicable in sandwich beams with a large span-to-depth ratio, it has some drawbacks. For example, it omits the transverse shear deformation of the beam when the span-to-depth ratio is rather small. The first-order shear deformation theory within the elastic region, which applies to shear deformable structures, predicts results that are in closer agreement with experiments (Carlsson \& Kardomateas, 2011). The classical EulerBernoulli beam theory was adopted for the deflection solution, where the midspan deflection $\delta$ is calculated according to Eq. (3):

$$
\begin{aligned}
& \delta_{\text {loading.point }}=\frac{P a}{2 k A G}+\frac{P a^{2} L}{4 E I}-\frac{P a^{3}}{3 E I}, \\
& \delta_{\text {mid.span }}=\frac{P a}{2 k A G}+\frac{P a L^{2}}{16 E I}-\frac{P a^{3}}{12 E I},
\end{aligned}
$$

where $P$ is the applied load, $L$ is the span length, $a$ is the distance between the support and the loading point (Figure 3 ), $k$ is the shear correction factor (assumed $=5 / 6$ ), $A G$ is the effective shear stiffness of the core, and $E I$ is the effective flexural stiffness of the sandwich bridge deck.

According to the plane section assumption, the flexural stiffness is equal to the sum of the flexural stiffness of each part; therefore, the flexural stiffness of sandwich deck is calculated according to Eq. (4):

$$
E I=4\left[2 E_{f} I_{f}+E_{c} I_{c}+2 E_{w} I_{w}\right] \text {, }
$$

where the face sheets are $E_{f} I_{f}=E_{f}\left[\frac{b t_{f}^{3}}{12}+b t_{f}\left(\frac{t_{f}+t_{c}}{2}\right)^{2}\right]$;

the core is $E_{c} I_{c}=E_{c} \frac{b_{c} t_{c}^{3}}{12}$, and the web is $E_{w} I_{w}=E_{f}\left[\frac{t_{w} t_{c}{ }^{3}}{12}+t_{w} t_{c}\left(\frac{t_{w}+b_{c}}{2}\right)^{2}\right]$.

Therefore, Eq. (2) is expressed according to Eq. (5):

$$
E I=8 E_{f}\left[\frac{b t_{f}^{3}}{12}+b t_{f} \frac{\left(t_{c}+t_{f}\right)^{2}}{4}+\frac{t_{w} t_{c}^{3}}{12}+t_{w} t_{c} \frac{\left(t_{w}+b_{c}\right)^{2}}{4}\right]+4 E_{c} \frac{b_{c} t_{c}^{3}}{12}
$$

where $t_{f}$ is the thickness of the face sheets; $b$ is the section width of the sandwich structure; $b_{c}$ and $t_{c}$ are the width and thickness of the core, respectively; and $t_{w}$ is the width of the web. Similarly, the shear stiffness of the bridge deck consists of three parts: the shear stiffness of the face 


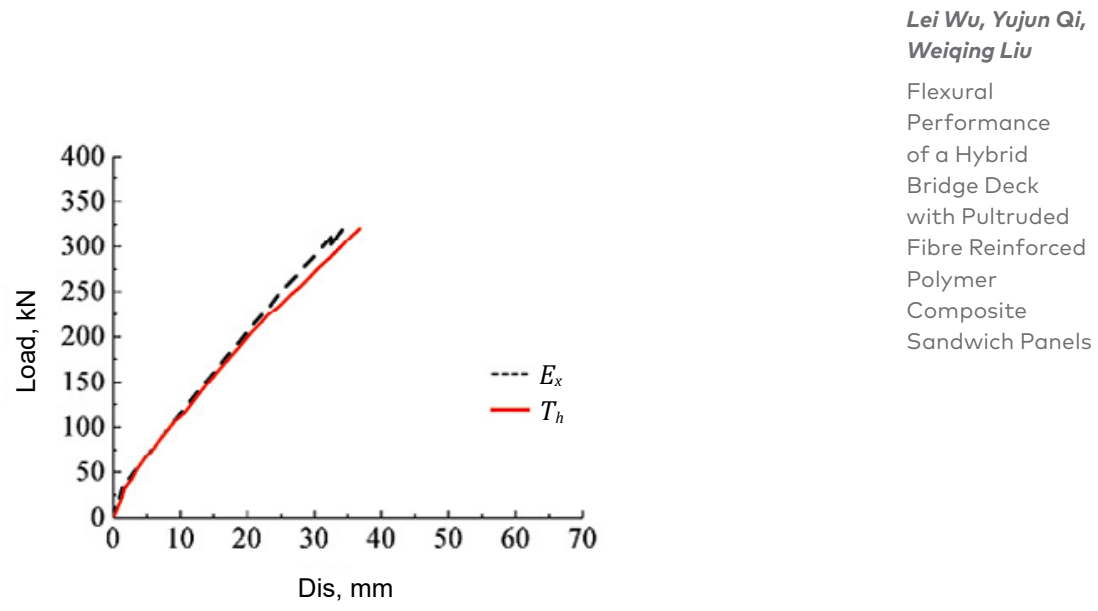

Figure 18. Theoretical and experimental values of the load-displacement curve

sheets, the shear stiffness of the web, and shear stiffness of the core (southern pine). Eq. (6) is derived from the similar principle of shear stiffness

$$
G A=4\left[2 G_{f} A_{f}+G_{c} A_{c}+2 G_{w} A_{w}\right],
$$

which is further reduced to Eq. (7)

$$
G A=8 G_{f}\left(b t_{f}+t_{w} t_{c}\right)+4 G_{c} b_{c} t_{c} .
$$

The numerical values (Ye, 2006) of the wood material test was incorporated into the above formulas $\left(E_{x}\right.$ and $T_{h}$ stand for the experimental value and theoretical value, respectively; Figure 18). The theoretical load-displacement curve under Load Case 1 (the fourpoint bending test) is derived. Figure 18 shows that the FSDT slightly underestimated the experimental deflection (Camata \& Shing, 2010). This variation likely occurred for two reasons. First, when calculating the theoretical values, the flexural stiffness and shear stiffness of the surface course were neglected in the calculation, which affected the results. Second, FSDT assumes a perfect bond between the facings, web, and core. However, debonding at the top face sheet occurred during the experiment, resulting in stiffness degradation. In general, the experimental values are in sufficiently good agreement with the theoretical values for project applications.

\section{Conclusions}

The behaviour of the proposed hybrid bridge deck for highway bridges was experimentally evaluated. Based on the study presented in this paper, the conclusions are summarized as follows:

1. This study proposed a hybrid bridge deck with pultruded fibre reinforced polymer sandwich panels, which are composed of an 
outer composite shell and an inner light wood core. This study investigated the pultrusion process, which is able to be used for industrial production on a factory pultrusion production line. Moreover, a continuous splicing operation is used for the bottom connection panels. This hybrid bridge deck has a better surface quality than those of composite sandwich panels made via the hand layer up process and vacuum infusion process. Therefore, it is applicable in engineering.

2. The maximum bearing capacity of the hybrid bridge deck under the three-studied working conditions are 3.8, 3.5 and 3.2 times the service load. This finding indicates that this hybrid bridge deck has a very high bearing capacity. Therefore, its application in bridge engineering is greatly promising. The application of bridge decks should consider the overload impact effect. Fibre reinforced polymer material have an excellent degree of reliability. Therefore, the design bearing capacity is above its service load, allowing for a certain degree of safety.

3. During the four-point bending test, the hybrid bridge deck with pultruded fibre reinforced polymer composite sandwich panels showed different failure modes. These modes included lateral shear failure of the upper panel, longitudinal shear failure at the intersection of the web and upper panel, and glass fibre rupture at the front and back sides. The failures decreased ultimate bearing capacity. The calculation methods for the ultimate bearing capacity for the different failure modes need to be further studied.

4. The proposed hybrid bridge deck with pultruded fibre reinforced polymer composite sandwich panels shows improved stiffness and strength. Furthermore, it is convenient and efficient. It is lighter than reinforced concrete bridge decks. The staggered connection steel plate at the bottom enables rapid and convenient installation of multiple bridge decks for large-scale assembly. Its construction is convenient with reduced labour cost. Thus, this design meets the state requirements.

5. All the hybrid bridge decks tested in different working conditions exhibited linear elastic behaviour until failure. Before the ultimate load, the tested decks showed a slight decrease in stiffness due to the microcracks on the surface and lateral fibre reinforced polymers.

Further research studies should be conducted with more samples and with the involvement of the industry considering the potential of this material, including laminated wood and reinforced laminated wood. These studies should consider such issues as how to enhance the performance of the interface between the fibre reinforced polymer and the wood core and how to improve the interlaminar shear strength of the fibre reinforced 
polymers to avoid early cracks in the web. Furthermore, optimization analysis is also needed for the thickness of the fibre reinforced polymer face sheets and the wood species. Finally, fibre reinforced polymers possess such merits as anti-corrosion, humidity resistance, and durability. If the fibre reinforced polymer bridge deck remains intact, the wood has excellent durability. However, the wood cannot withstand humidity, and when the fibre reinforced polymers are applied in coastal areas, they are prone to be infested by insects after failure. Therefore, it is necessary to conduct further research on the wood and its overall durability.

\section{Acknowledgements}

The support from the National Key R\&D Program of China (2017YFC0703006) and the National Natural Science Foundation of China (Grant No. 51578285 and 51778286) and the Natural Science Foundation of Jiangsu Province (Grant No. BK20171469) are acknowledged.

\section{REFERENCES}

Andor, K., Lengyel, A., Polgár, R., Fodor, T., \& Karácsonyi, Z. (2015). Experimental and statistical analysis of spruce timber beams reinforced with CFRP fabric. Construction and Building Materials, 99, 200-207. https://doi.org/10.1016/j.conbuildmat.2015.09.026

ASTM D-143 (2000). Standard Test Methods for Small Clear Specimens of Timber. ASTM, PA, USA.

ASTM D695-10 (2010). Standard Test Method for Compressive Properties of Rigid Plastics. ASTM, PA, USA.

Bakis, C. E., Bank, L. C., Brown, V., Cosenza, E., Davalos, J. F., Lesko, J. J., ... \& Triantafillou, T. C. (2002). Fiber-reinforced polymer composites for construction-State-of-the-art review. Journal of composites for construction, 6(2), 73-87. https://doi.org/10.1061/(ASCE)1090-0268(2002)6:2(73)

Camata, G., \& Shing, P. B. (2010). Static and fatigue load performance of a GFRP honeycomb bridge deck. Composites Part B: Engineering, 41(4), 299-307. https://doi.org/10.1016/j.compositesb.2010.02.005

Carlsson, L. A., \& Kardomateas, G. A. (2011). Structural and failure mechanics of sandwich composites. Springer Science \& Business Media. https://doi.org/10.1007/978-1-4020-3225-7

Cedolin, L. (2010). Stability of structures: elastic, inelastic, fracture and damage theories. World Scientific.

Davalos, J. F., Qiao, P., Xu, X. F., Robinson, J., \& Barth, K. E. (2001). Modeling and characterization of fiber-reinforced plastic honeycomb sandwich panels for highway bridge applications. Composite structures, 52(3-4), 441-452. https://doi.org/10.1016/S0263-8223(01)00034-4

Feng, P.; \& Ye, L. P. (2004). Analysis and Experimental Study of Statically Loaded GFRP Hollow Slab [J]. Industrial Construction, 34(4),15-18,27 (in Chinese)
Performance

of a Hybrid

Bridge Deck

with Pultruded

Fibre Reinforced

Polymer

Composite

Sandwich Panels 
Fairuz, A. M., Sapuan, S. M., Zainudin, E. S., \& Jaafar, C. N. A. (2014). Polymer composite manufacturing using a pultrusion process: a review. American Journal of Applied Sciences, 11(10), 1798-1810.

Franke, S., Franke, B., \& Harte, A. M. (2015). Failure modes and reinforcement techniques for timber beams-State of the art. Construction and Building Materials, 97, 2-13. https://doi.org/10.1016/j.conbuildmat.2015.06.021

Gan, L. H., Ye, L., \& Mai, Y. W. (1999). Design and evaluation of various section profiles for pultruded deck panels. Composite structures, 47(1-4), 719-725. https://doi.org/10.1016/S0263-8223(00)00042-8

Hollaway, L. (1993). Polymer composites for civil and structural engineering. Blackie Academic \& Professional 12, 104.

Ji, H. S., Byun, J. K., Lee, C. S., Son, B. J., \& Ma, Z. J. (2011). Structural performance of composite sandwich bridge decks with hybrid GFRP-steel core. Composite Structures, 93(2), 430-442. https://doi.org/10.1016/j.compstruct.2010.08.037

Keller, T. (2001). Recent all-composite and hybrid fibre-reinforced polymer bridges and buildings. Progress in Structural Engineering and Materials, 3(2), 132-140. https://doi.org/10.1002/pse.66

Keller, T., \& Schollmayer, M. (2004). Plate bending behavior of a pultruded GFRP bridge deck system. Composite Structures, 64(3-4), 285-295. https://doi.org/10.1016/j.compstruct.2003.08.011

Keller, T., Schaumann, E., \& Vallée, T. (2007). Flexural behavior of a hybrid FRP and lightweight concrete sandwich bridge deck. Composites Part A: Applied Science and Manufacturing, 38(3), 879-889.

https://doi.org/10.1016/j.compositesa.2006.07.007

Lee, S. W., \& Hong, K. J. (2007a). Constructing bridges with glass-fiber reinforced composite decks. Proceedings of 4th International Structural Engineering and Construction.

Lee, S. W., \& Hong, K. J. (2007b, March). Experiencing more composite-deck bridge and developing innovative profile of snap-fit connections. In Proceedings of COBRAE Conference.

Li, Y. F., Tsai, M. J., Wei, T. F., \& Wang, W. C. (2014). A study on wood beams strengthened by FRP composite materials. Construction and Building Materials, 62, 118-125. https://doi.org/10.1016/j.conbuildmat.2014.03.036

Liu, Z. H. (2007). Testing and analysis of a fibre reinforced polymer deck (PhD thesis). Virginia Tech, Blacksburg, VA.

Lu, W., Ling, Z., Geng, Q., Liu, W., Yang, H., \& Yue, K. (2015). Study on flexural behaviour of glulam beams reinforced by Near Surface Mounted (NSM) CFRP laminates. Construction and Building Materials, 91, 23-31. https://doi.org/10.1016/j.conbuildmat.2015.04.050

Manalo, A. C., Aravinthan, T., \& Karunasena, W. (2010). Flexural behaviour of glue-laminated fibre composite sandwich beams. Composite Structures, 92(11), 2703-2711. https://doi.org/10.1016/j.compstruct.2010.03.006

Park, K. T., Kim, S. H., Lee, Y. H., \& Hwang, Y. K. (2005). Pilot test on a developed GFRP bridge deck. Composite structures, 70(1), 48-59.

https://doi.org/10.1016/j.compstruct.2004.08.011 
Park, S. Z.; Lee, S. W.; Hong, K. J. (2010). Current and future applications of glass-fibre-reinforced polymer decks in Korea. Structural Engineering International 20(4), 405-408.

Park, S. Z., Hong, K. J., \& Lee, S. W. (2014). Behavior of an adhesive joint under weak-axis bending in a pultruded GFRP bridge deck. Composites Part B: Engineering, 63, 123-140. https://doi.org/10.1016/j.compositesb.2014.04.002

Qiao, P., Davalos, J. F., \& Brown, B. (2000). A systematic analysis and design approach for single-span FRP deck/stringer bridges. Composites Part B: Engi neering, 31(6-7), 593-609. https://doi.org/10.1016/S1359-8368(99)00044-X

Raftery, G. M., \& Whelan, C. (2014). Low-grade glued laminated timber beams reinforced using improved arrangements of bonded-in GFRP rods. Construction and building materials, 52, 209-220. https://doi.org/10.1016/j.conbuildmat.2013.11.044

Reising, R. M., Shahrooz, B. M., Hunt, V. J., Neumann, A. R., Helmicki, A. J., \& Hastak, M. (2004). Close look at construction issues and performance of four fiber-reinforced polymer composite bridge decks. Journal of Composites for Construction, 8(1), 33-42. https://doi.org/10.1061/(ASCE)1090-0268(2004)8:1(33)

Salim, H. A., Davalos, J. E., Qiao, P., \& Kiger, S. A. (1997). Analysis and design of fiber reinforced plastic composite deck-and-stringer bridges. Composite structures, 38(1-4), 295-307. https://doi.org/10.1016/S0263-8223(97)00064-0

Telang, N. M.; Dumlao, C.; Mehrabi, A. B.; Ciolko, A. T.; \& Gutierrez, J. (2006). Field inspection of in-service FRP bridge decks (No. 564). Transportation Research Board.

Triandafilou, L. N., \& O'Connor, J. S. (2010). Field issues associated with the use of fiber-reinforced polymer composite bridge decks and superstructures in harsh environments. Structural Engineering International, 20(4), 409-413. https://doi.org/10.2749/101686610793557663

Wu, W. Q., Ye, J. S., Wan, S., \& Hu, C. (2005). Quasi Plane Assumption and Its Application in Steel-Concrete Composite Box Girders With Corrugated Steel Webs [J]. Engineering Mechanics, 5, 031.

Yashida, N.; Praveen, N.; Mohammed, A.; Muhammed, A. M. (2016). Flexural stiffness and strength enhancement of horizontally glued laminated wood beams with GFRP and CFRP composite sheets. Constr Build Mater 112, 547-555.

Ye, L. P.; Feng, P. (2006). Applications and development of fibre-reinforced polymer in engineering structures. China Civil Engineering Journal 9(3), 24-36.

Zhu, K. N., Wan, S., \& Liu, Y. Q. (2010). Analysis and Experimental Study on Statically Loaded FRP Bridge Deck. Engineering Mechanics, S1.

Zi, G., Kim, B. M., Hwang, Y. K., \& Lee, Y. H. (2008). The static behavior of a modular foam-filled GFRP bridge deck with a strong web-flange joint. Composite Structures, 85(2), 155-163. https://doi.org/10.1016/j.compstruct.2007.10.015

Zureick, A. (1997). Fibre reinforced polymer bridge decks. Proc. National Seminar on Advanced Composite Material Bridges. FHWA. 